\section{New equipment to prevent carbon dioxide rebreathing during eye surgery under retrobulbar anaesthesia}

\author{
A Schlager, Hubert Staud
}

\begin{abstract}
Background-Carbon dioxide concentration under ophthalmic drapes increases during eye surgery under local anaesthesia. A new prototype has been designed which combines continuous suction of carbon dioxide enriched air and continuous oxygen insufflation under ophthalmic drapes to prevent carbon dioxide accumulation in spontaneously breathing patients undergoing cataract surgery.

Methods-In a prospective randomised single blind study the effectiveness of this new prototype was examined in 50 unpremedicated elderly patients. In 25 patients suction was applied under ophthalmic drapes, whereas in the other 25 patients no suction was used. In all cases oxygen was insufflated under the drapes at a constant flow of $21 / \mathrm{min}$. Carbon dioxide concentration in the ambient air surrounding the patient's head under ophthalmic drapes, transcutaneous partial pressure of carbon dioxide, respiratory rate, and oxygen saturation were measured.

Results-Carbon dioxide concentration under the drapes, transcutaneous partial pressure of carbon dioxide, and respiratory rate remained unchanged in the suction group, whereas in the non-suction group these values increased significantly. Oxygen saturation rose significantly in both groups without differences between the groups.
\end{abstract}

Conclusion-Application of this new prototype for continuous aspiration of carbon dioxide enriched air prevents carbon dioxide rebreathing and subsequent hypercapnia associated with an elevated respiratory rate. This new equipment may therefore be useful in patients undergoing ophthalmic surgery under retrobulbar anaesthesia.

(Br f Ophthalmol 1999;83:1131-1134)

General Intensive Care

Medicine, Division of

Anaesthesia, The

Leopold Franzens

University of

Innsbruck, Austria

A Schlager

H Staud

Correspondence to:

Dr Andreas Schlager,

Department of Anaesthesia and General Intensive Care

Medicine, Anichstrasse 35,

A-6020 Innsbruck, Austria.

Accepted for publication 17 June 1999

An intraoperative increase in arterial partial pressure of carbon dioxide due to rebreathing of exhaled carbon dioxide under ophthalmic drapes has been reported in patients undergoing ophthalmic surgery under retrobulbar anaesthesia. ${ }^{12}$ Carbon dioxide exhaled by the patient escapes only partially through ophthalmic drapes and hence results in an increase in carbon dioxide in the ambient air around the patient's head. ${ }^{2-6}$ High oxygen flows with and without suction have been described for reducing the carbon dioxide concentration under the
Anarthent of drapes using hoops and suction with particularly high fresh gas flows of $5-10 \mathrm{l} / \mathrm{min}^{46}$ Technical problems found when using similar previously designed equipment ${ }^{4}{ }^{6}$ (for example, difficult placement of the surgical microscope) prompted us to design a new prototype combining both suction and oxygen insufflation.

The aim of the present study was to examine the effectiveness of this new prototype in spontaneously breathing geriatric patients undergoing cataract surgery.

\section{Materials and methods}

The university ethics committee approved the study protocol. After receiving written informed consent, 50 unpremedicated patients (ASA 1-3) scheduled for cataract surgery under retrobulbar anaesthesia were examined in a randomised, single blind manner.

Patients with pre-existing pulmonary disease, neurological or psychiatric disorders, and severe cardiovascular, renal, or hepatic dysfunction, or patients needing intraoperative sedation or additional opiate analgesia were excluded from the study.

\section{EQUIPMENT FOR SUCTION AND OXYGEN}

INSUFFLATION

The design of the new equipment and its position during surgery are shown in Figure 1. One end of a flexible $750 \mathrm{~mm}$ long plastic tube (12 $\mathrm{mm}$ inner diameter) consisting of 36 ball and socket elements (Lock Line, Lock Wood Productions, Lake Oswego, OR, USA) is attached to a metal connecting tube rigidly fixed to a rod clamped to a bar along the operating table. Inserted in the other end of the tube is a $\mathrm{Y}$ connector, and its two free ends each hold a transparent $120 \mathrm{~mm}$ long curved suction tube (12 mm ID) (Fig 1, B). The underside of each of these transparent tubes has a row of three apertures, $6 \mathrm{~mm}$ in diameter and $25 \mathrm{~mm}$ apart, and the end of each tube is part of the equipment is placed over the chin of the patient. Suction is performed at 800 mbars using a conventional suction device for anaesthetic gas. A small flexible plastic tube $(4 \mathrm{~mm}$ ID) taped along the ball and socket elements provides oxygen supply (Fig 1, C). The tip of a sampling tube fixed to the underside of the $\mathrm{Y}$ piece is used to measure the concentration of carbon dioxide and oxygen under the drapes (Fig 1, A). 


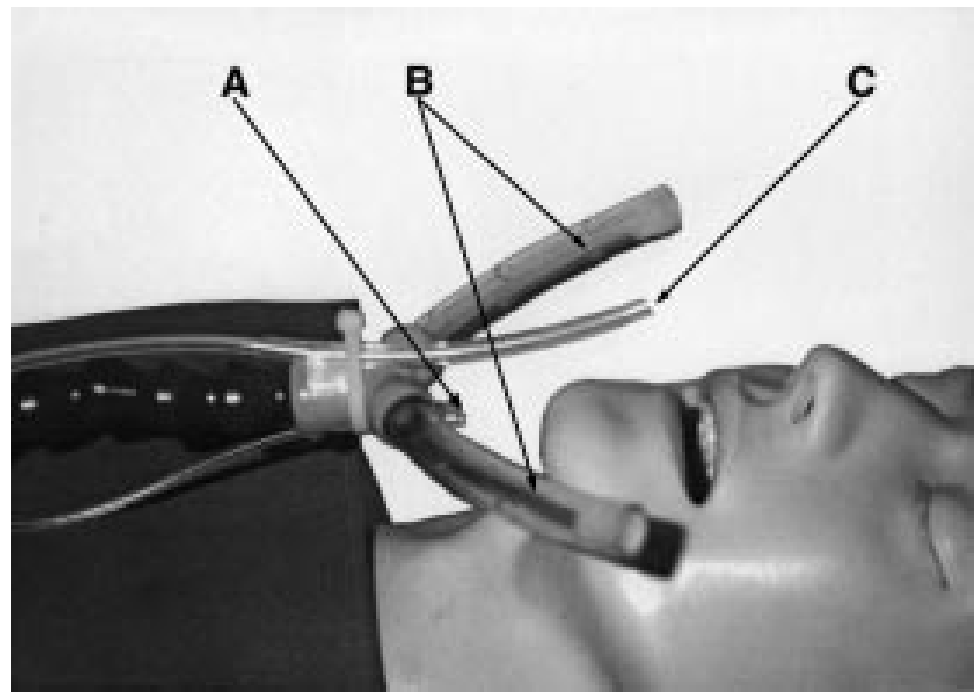

Figure 1 Design and position of the prototype during surgery: probe for measuring carbon dioxide and oxygen concentration under the drapes $(A)$, suction tubes $(B)$, and oxygen probe $(C)$ in a model without drapes.

\section{STUDY DESIGN}

Patients were randomly allocated to one of two study groups comprising 25 people each. While in one group patients were provided with suction and oxygen supply ( $2 \mathrm{l} / \mathrm{min})$, the other group received only oxygen insufflation with $2 \mathrm{l} / \mathrm{min}$. Heart rate (HR), peripheral oxygen saturation $\left(\mathrm{Spo}_{2}\right)$ and non-invasive mean arterial blood pressure (MAP) were continuously measured using a standardised monitor (Cardiocap, Datex, Helsinki, Finland).

After the ophthalmic surgeon induced retrobulbar anaesthesia, the study equipment was placed over the chin of the patient as shown in Figure 1. A large drape was placed over each patient, fully covering him except for the head. The patient's head was covered with a sterile cotton drape having a central, circular aperture (80 $\mathrm{mm}$ in diameter) over the eye to be operated. An ophthalmic drape (Steri Drape $1024,3 \mathrm{M}$ ) measuring $460 \times 390 \mathrm{~mm}$ was placed over the cotton drape. Immediately after draping the patient's head oxygen $21 / \mathrm{min}$ was continuously insufflated through the oxygen tube in each group. In the suction group the ambient air was also suctioned off during the entire course of the operation.

As soon as the operation was completed, the drapes were removed from the head and the suction equipment withdrawn.

\section{VARIABLES MEASURED}

- Carbon dioxide concentration in the ambient air surrounding the patient's head under the drapes $\left(\mathrm{pCO}_{2}\right)$ : Carbon dioxide was measured with

Table 1 Demographic data and baseline values expressed in numbers and mean (SD). Baseline values were measured before draping

\begin{tabular}{llllll}
\hline Demographics & S group & NS group & Baseline values & S group & NS group \\
\hline Sex (F/M) & $12 / 12$ & $13 / 11$ & $\mathrm{p}_{\mathrm{tc}} \mathrm{CO}_{2}(\mathrm{~mm} \mathrm{Hg})$ & $43.4(4.4)$ & $42.5(4.6)$ \\
Age (years) & $72.8(7.1)$ & $73.16(7.2)$ & $\mathrm{RR}(/ \mathrm{min})$ & $15.2(2.1)$ & $14.5(1.7)$ \\
Body weight $(\mathrm{kg})$ & $69.14(11.5)$ & $75.7(13.3)$ & $\mathrm{SpO}_{2}(\%)$ & $95.6(0.9)$ & $95.3(0.9)$ \\
Height $(\mathrm{cm})$ & $166.6(7.2)$ & $168.8(9.3)$ & $\mathrm{MAP}(\mathrm{mm} \mathrm{Hg})$ & $104.8(11.1)$ & $105.3(12.3)$ \\
ASA physical status & $2.0(0.3)$ & $2.0(0.3)$ & $\mathrm{HR}($ beats $/ \mathrm{min})$ & $66.2(12.5)$ & $70.0(13.2)$
\end{tabular}

$\mathrm{S}$ group $=$ continuous suction under the drapes; $\mathrm{NS}$ group $=$ no suction under the drapes; $\mathrm{p}_{\mathrm{tc}} \mathrm{CO}_{2}$ $=$ partial pressure of carbon dioxide $\mathrm{RR}=$ respiratory rate $\mathrm{Spo}_{2}=$ peripheral oxygen saturation $\mathrm{MAP}=$ mean arterial blood pressure; $\mathrm{HR}=$ heart rate. an anaesthesia monitor (Cardiocap Datex, Helsinki, Finland). To prevent variations in the carbon dioxide curves caused by the patient's breathing, a collection reservoir $(150 \mathrm{ml})$ was placed in the line of the gas sampling tube.

- Transcutaneous partial pressure of carbon dioxide $\left(\mathrm{P}_{\mathrm{tc}} \mathrm{CO}_{2}\right)$ measurement: (TCM 3 Monitor, Radiometer, Copenhagen, Denmark). Calibration of the measuring electrode was performed at $43^{\circ} \mathrm{C}$ using a standardised carbon dioxide/oxygen/nitrogen gas mixture $(5 \%$ carbon dioxide, $20.9 \%$ oxygen, nitrogen balanced). The electrode for $\mathrm{p}_{\mathrm{tc}} \mathrm{CO}_{2}$ measurements was placed on the left lateral thorax at the level of the fourth intercostal space.

- Respiratory rate (RR): Thoracic excursions were counted for a period of 1 minute at each measurement time.

- Heart rate (HR), non-invasive mean arterial blood pressure (MAP), and peripheral oxygen saturation by pulse oxymetry $\left(\mathrm{SpO}_{2}\right)$ were measured with an anaesthesia monitor (Cardiocap, Datex, Helsinki, Finland).

Baseline values were obtained immediately before the patient's head was draped. Additional measurements were taken at 3, 6, 9, 12, 15 minutes after draping the head, and then at 5 minute intervals until the end of surgery (drape removed from head) as well as 5 minutes after complete removal of the remaining drapes.

\section{STATISTICAL ANALYSIS}

For statistical analysis sPSs 7.5 (SPSS Inc, Chicago, IL, USA) was used. Demographic data were compared by using the unpaired $t$ test. Overall effects within and between the groups were evaluated by repeated measurement analysis of variance (ANOVA). In the case of significant differences, further comparisons between groups at individual times were made with the unpaired two tailed $t$ test. $\mathrm{p} \leqslant 0.05$ was considered statistically significant. The Bonferroni test was used for correction of multiple comparison. Results are expressed as mean (SD).

\section{Results}

Forty eight patients were enrolled in the study. Two patients were excluded from data analysis because one needed additional opiate analgesia and the other developed intraoperative psychic disorders.

Demographic data and baseline measurements were similar in both groups (Table 1). During the investigative period no significant differences in MAP and HR were measured either within or between the groups. Three minutes after starting oxygen insufflation the $\mathrm{SpO}_{2}$ values rose significantly in both groups without differences between the groups (suction group: $95.6 \%(0.9)$ to $97.9 \%$ (1.1), p $\leqslant 0.0001$; non-suction group: $95.3 \%(0.9)$ to $97.5 \%(0.9), \mathrm{p}=0.0012)$.

Covering the patient's head increased the ambient carbon dioxide concentration $\left(\mathrm{pco}_{2}\right)$ in the non-suction group when compared with the suction group from five-sixfold at 3 minutes to 14 -fold at 30 minutes $(\mathrm{p} \leqslant 0.001)$, 


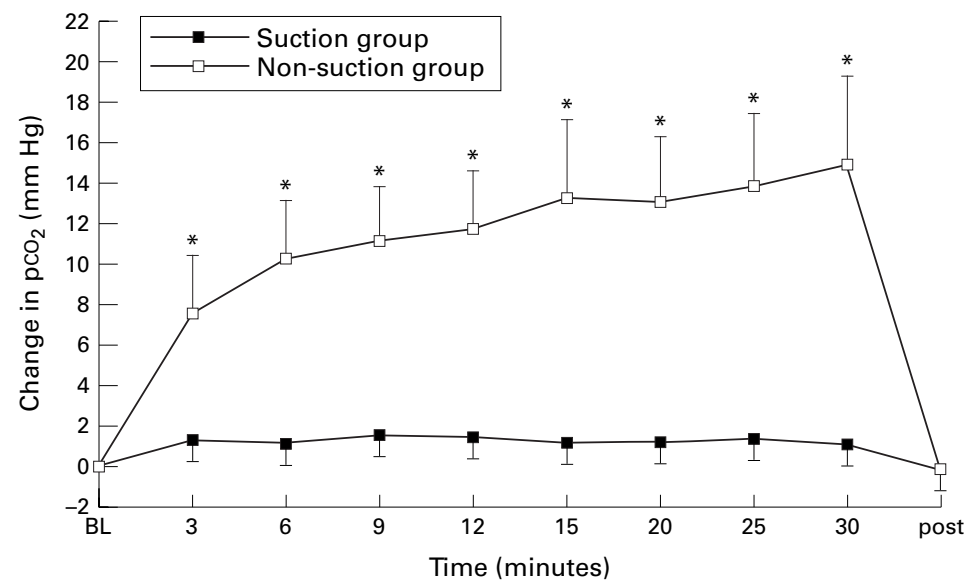

Figure 2 Delta values (mean (SD)) of carbon dioxide partial pressure ( $\mathrm{pCO}_{2}$ ) under the drapes during cataract surgery under retrobulbar anaesthesia. Baseline values $(B L)$ were measured before draping. Further values were measured after covering the head. Last measurement (post) was taken 5 minutes after removal of the drapes. ${ }^{\star} p<0.05$, comparing the suction group and the non-suction group (unpaired t test).

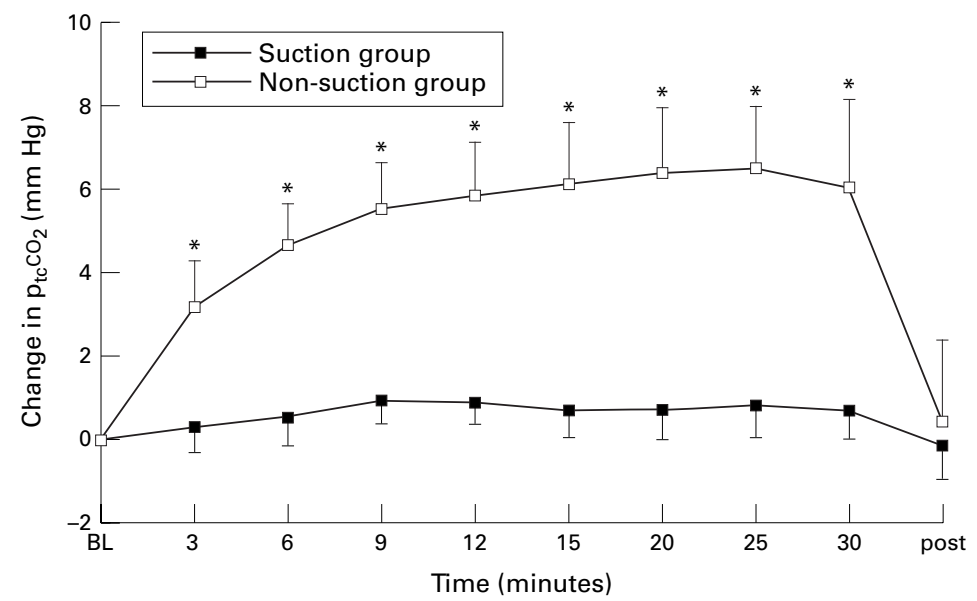

Figure 3 Delta values (mean (SD)) of transcutaneous measured pressure of carbon dioxide $\left(p_{t c} \mathrm{CO}_{2}\right)$ during cataract surgery under retrobulbar anaesthesia. Baseline values (BL) were measured before draping. Further values were measured after covering the head. Last measurement (post) was taken 5 minutes after removal of the drapes. ${ }^{\star} p<0.05$, comparing the suction group and the non-suction group (unpaired t test).

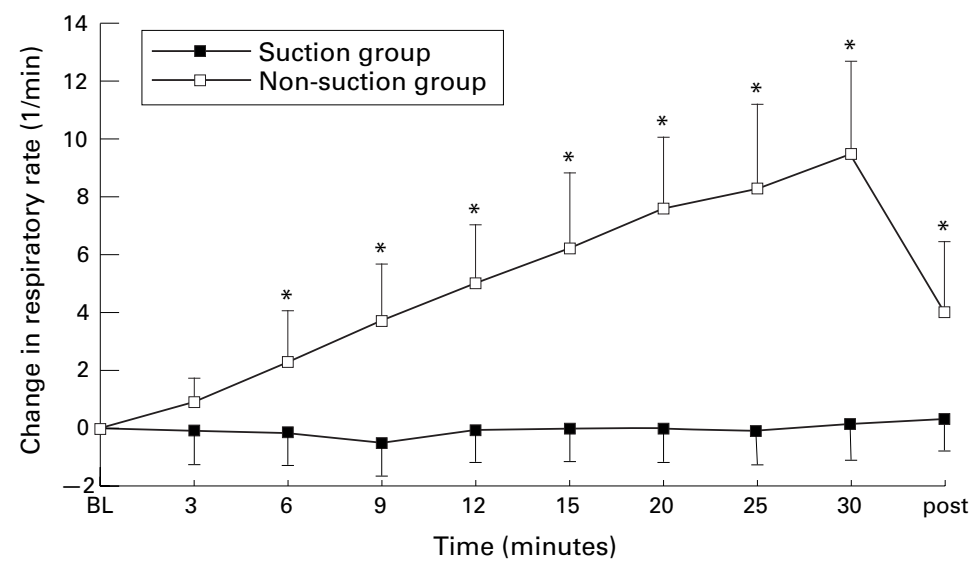

Figure 4 Delta values (mean (SD)) of respiratory rate $(R R)$ during cataract surgery under retrobulbar anaesthesia. Baseline values $(B L)$ were measured before draping. Further values were measured after covering the head. Last measurement (post) was taken 5 minutes after removal of the drapes. ${ }^{\star} p<0.05$, comparing the suction group and the non-suction group (unpaired t test). causing a significant increase in $\mathrm{RR}$ and $\mathrm{p}_{\mathrm{tc}} \mathrm{CO}_{2}$ in the non-suction group (Fig 2). $\mathrm{RR}$ and $\mathrm{p}_{\mathrm{tc}} \mathrm{CO}_{2}$ remained constant in the suction group throughout the investigative period. In the non-suction group $\mathrm{p}_{\mathrm{tc}} \mathrm{CO}_{2}$ values (Fig 3 ) and $\mathrm{RR}$ (Fig 4) increased significantly immediately after covering the patient's head and rose in the further course of the operation. In both groups $\mathrm{RR}, \mathrm{pCO}_{2}$, and $\mathrm{p}_{\mathrm{tc}} \mathrm{CO}_{2}$ values again approximated the baseline values 5 minutes after removal of the drapes.

\section{Discussion}

The results of the present study show that our new device, which is easy to handle, prevents rebreathing of carbon dioxide in spontaneously breathing patients undergoing intraocular surgery and the subsequent rise in $\mathrm{p}_{\mathrm{tc}} \mathrm{CO}_{2}$ and respiratory rate owing to the rebreathing of carbon dioxide.

In the clinical use of previously described equipment for continuous suction and oxygen insufflation ${ }^{4}{ }^{6}$ we observed several problems. In some cases the surgeons had trouble placing the surgical microscope and in other cases the nursing staff complained about being hindered when passing the surgical instruments to the surgeon. In contrast, the above mentioned problems were not seen when using our prototype. We were able to adapt our device to fit not only the needs of the patient but also the operating conditions. Additionally, our equipment has the advantage of being permanently fixed to the operating table while still swinging aside to let patients take position.

Our results extended previously reported findings in carbon dioxide accumulation under ophthalmic drapes during eye surgery. ${ }^{2-6}$ In our non-suction patients, carbon dioxide concentration under the drapes rose immediately after covering the patient's head. Although carbon dioxide rebreathing and hypercapnia led to a compensatory increase in respiratory rate ${ }^{7}$ the patients were not able to keep their $\mathrm{p}_{\mathrm{tc}} \mathrm{CO}_{2}$ values within the normal range.

Sufficient suction of part of the carbon dioxide enriched air or a high oxygen flow under the drapes has been shown to be of outstanding importance in removing the carbon dioxide enriched air accumulating under sterile ophthalmic drapes. ${ }^{2-6}$ Ramanathan et $a l^{4}$ examined unsedated volunteers using a special hoop for suction and oxygen supply. Without any suction or oxygen insufflation carbon dioxide concentration under the drapes reached 3.5\% 15 minutes after covering. Suction and oxygen supply at $10 \mathrm{l} / \mathrm{min}$ in their study decreased the carbon dioxide concentration under the drapes to $0.2 \%$.

Zeitlin et $a l^{6}$ conducted their study in patients and in laboratory experiments. Examining carbon dioxide concentrations under drapes in patients, they found only a small decrease in $\mathrm{pCO}_{2}$ from $10.1 \mathrm{~mm} \mathrm{Hg}$ without suction to $7.9 \mathrm{~mm} \mathrm{Hg}$ with suction at a fresh gas flow of $5 \mathrm{l} / \mathrm{min}$. Using $10 \mathrm{l} / \mathrm{min}$ fresh gas flow $\mathrm{pCO}_{2}$ decreased to a minimal value of 4.9 $\mathrm{mm} \mathrm{Hg}$. Because of these still high $\mathrm{pCO}_{2}$ values, their method does not seem able to reduce carbon dioxide concentration under ophthalmic 
drapes sufficiently to prevent carbon dioxide rebreathing in spontaneously breathing patients during eye surgery. In contrast with the work by Zeitlin et $a l^{6}$ our equipment prevents carbon dioxide accumulation under ophthalmic drapes. Suction and oxygen supply at 2 $1 /$ min ensure constant low $\mathrm{pCO}_{2}$ values at 1.35 $\mathrm{mm} \mathrm{Hg}$ under ophthalmic drapes without an increase in $\mathrm{p}_{\mathrm{tc}} \mathrm{CO}_{2}$ or in respiratory rate in our patients. These data led us to assume that no carbon dioxide rebreathing occurred in this study group.

The present study comprised only patients with no known pulmonary disorders and no sedation. Therefore, we cannot make any statements concerning $\mathrm{p}_{\mathrm{tc}} \mathrm{CO}_{2}$ values and respiratory rate in patients with impaired pulmonary function or in sedated patients. However, it may be assumed that carbon dioxide retention is more pronounced in patients with pre-existing pulmonary disorders and in patients undergoing surgery under rescue breathing apparatus (RBA) with additional sedation. Higher arterial $\mathrm{pCO}_{2}$ values result in raised choroidal blood flow and intraocular pressure. ${ }^{89}$ This in turn may complicate the operation and aggravate outcome. ${ }^{10}$

Additionally, we found an oxygen flow of 2 $1 /$ min sufficient to keep $\mathrm{SpO}_{2}$ values within normal ranges. In contrast with previous investigations, ${ }^{46}$ no high flow of oxygen was necessary in our study to prevent hypercapnia and hypoxia when combined with suction. Cummings et al, who administered air or oxygen at a flow of $5 \mathrm{l} / \mathrm{min}$, questioned the benefit of pure oxygen insufflation during surgery under RBA. ${ }^{11}$ In contrast, other authors have suggested the use of low flow oxygen supplementation for all patients undergoing ophthalmic surgery under local anaesthesia. ${ }^{12} 13$
We found our newly designed suction equipment easy to handle and useful in preventing carbon dioxide accumulation, carbon dioxide rebreathing, and unwanted tachypnoea and exhaustion of patients. The addition of a low flow oxygen supply $(2 \mathrm{l} / \mathrm{min})$ is a simple means of providing normoxaemia. In conclusion, the equipment presented here is beneficial for practical use in elderly patients undergoing eye surgery under retrobulbar anaesthesia.

The authors gratefully acknowledge the assistance provided by the surgeons and the nursing staff of the clinic of ophthalmology and optometry of the University of Innsbruck.

1 Heinze J, Rohrbach M. General anesthesia vs retrobulbar anesthesia in cataract surgery. A randomized comparison of anesthesia in cataract surgery. A randomized

2 Schlager A, Lorenz IH, Luger TJ. Transcutaneous $\mathrm{CO}_{2} / \mathrm{O}_{2}$ and $\mathrm{CO}_{2}$ /air suction in patients undergoing cataract surgery with retrobulbar anaesthesia. Anaesthesia 1998;53: surgery with 1212 .

3 Kobel M, Rifat K, Roth A. Accumulation of carbon dioxide in the operative field in ophthalmic interventions under local anesthesia. Ophthalmologica 1984;188:135-40.

4 Ramanathan S, Capan L, Chalon J, et al. Minienvironmental control under the drapes during operations on the eyes of conscious patients. Anesthesiology 1978;48:286-8.

5 Sabo B, Smith RB, Gilbert TJ. Evaluation of rebreathing in patients undergoing cataract surgery. Ophthalmic Surg 1988;19:249-51.

6 Zeitlin GL, Hobin K, Platt J, et al. Accumulation of carbon dioxide during eye surgery. F Clin Anesth 1989;1:262-7.

7 Nunn JF. Applied respiratory physiology. 4th ed. Oxford: Butterworth-Heinemann, 1993.

8 Hvidberg A, Kessing SV, Fernandes A. Effect of changes in $\mathrm{PCO}_{2}$ and body positions on intraocular pressure during general anaesthesia. Acta Ophthalmol 1981;59:465-75.

9 Riva CE, Cranstoun SD, Grunwald JE, et al. Choroidal blood flow in the foveal region of the human ocular fundus. Invest Ophthalmol Vis Sci 1994;35:4273-81.

10 Speaker MG, Guerriero PN, Met JA, et al. A case-control tudy of risk factors for intraoperative suprachoroida expulsive hemorrhage. Ophthalmology 1991;98:202-9.

11 Cummings AB, König HL. Effect of oxygen and air inhalation during cataract surgery on blood gas parameters. $\mathcal{F}$ Cataract Refract Surg 1996;22:1236-9.

12 Michelson $\mathrm{G}$, Naujoks $\mathrm{B} . \mathrm{O}_{2}$ administration by a nasal probe improves respiration in cataract surgery after retrobulbar anesthesia. Ophthalmic Surg 1991;22:615-18.

13 Risdall JE, Geraghty IF. Oxygenation of patients undergoing ophthalmic surgery under local anaesthesia. Anaesthesia 1997;52:492-5. 